\title{
SOLUÇÃo OXIDANTE GERADA A PARTIR DA ELETRÓLISE DE REJEITOS DE DESSALINIZADORES DE ÁGUA
}

\section{OXIDANT SOLUTION GENERATED BY ELECTROLYSIS FROM RESIDUE OF WATER DESALINATORS}

\section{JERUZA FEITOSA DE MATOS}

Engenheira Química pela UFC, mestre em Saneamento pela UFC e engenheira do Núcleo de Tecnologia Industrial (Nutec)

SUETONNIO MOTA

Engenheiro Civil pela UFC, mestre e doutor em Saúde Pública pela USP, professor titular do Departamento de Engenharia

Hidráulica e Ambiental da UFC.

\author{
FRANCIMEYRE FREIRE AVELINO \\ Química Industrial pela UFC.
}

VALTER LÚCIO DE PÁdUA

Engenheiro Civil pela UFMG, mestre e doutor em Hidráulica e Saneamento pela EESC-SP, professor adjunto do Departamento de Engenharia Sanitária e Ambiental da UFMG.

\section{ERIKA DE ALMEIDA SAMPAIo BRAGa}

Química Industrial pela UFC e estudante de mestrado em Saneamento na UFC.

\section{JACKON QUEIROZ MALVEIRA}

Técnico em Química do Nutec

Recebido: 03/05/05 Aceito: 30/01/06

\section{RESUMO}

Neste trabalho foram realizados estudos para a produção de solução oxidante a partir de rejeito de dessalinizadores de água pelo processo de eletrólise, visando a sua utilização como desinfetante. $\mathrm{O}$ experimento foi realizado em escala de laboratório. Três soluçōes oxidantes foram geradas eletroliticamente, a partir de rejeitos de dessalinizadores de água com concentraçôes de $1,7 \times 10^{3} \mathrm{mg} ; 5,5 \times 10^{3} \mathrm{mg}$ e $10,2 \times 10^{3} \mathrm{mg}$ de Cl-/L. O processo de eletrólise tinha duração de oito horas e, a cada hora da reação, o $\mathrm{pH}$, a condutividade elétrica, a temperatura e o cloro total eram monitorados. Foi observado que a produção de cloro está diretamente relacionada com a concentração de cloreto; o teor médio de cloro das soluçōes oxidantes geradas foi de $0,10 \% ; 0,24 \%$ e $0,27 \% \mathrm{~m} / \mathrm{m}$.

PALAVRAS-CHAVE: Dessalinização, osmose reversa, rejeito, eletrólise, solução oxidante, impactos ambientais.

\begin{abstract}
This work carried out studies about the use of the electrolysis process to produce oxidant solutions from water desalinators wastes for water disinfection. The experiment was conducted in laboratory scale. Three oxidant solutions were generated by electrolysis from wastes of water desalinators that presented concentrations of $1.7 \times 10^{3} \mathrm{mg}, 5.5 \times 10^{3} \mathrm{mg}$ and $10.2 \times 10^{3} \mathrm{mg}$ of $\mathrm{Cl} / \mathrm{L}$. The electrolysis process lasted eight hours and the following parameters were monitored every hour: $p H$, electrical conductivity, temperature, total chlorine. It was observed that the production of chlorine is directly related to chloride concentration; the average content of chlorine of the oxidant solutions generated from the desalinators wastes was $0.10 \%, 0.24 \%$ and $0.27 \% \mathrm{~m} / \mathrm{m}$.
\end{abstract}

KEYWORDS: Desalination; reverse osmosis; residue; electrolysis; oxidant solution; environmental impacts.

\section{INTRODUÇÃO}

Diversas são as ações governamentais com vistas a amenizar os problemas gerados pela seca, principalmente no que se refere à disponibilidade de água para o consumo humano. A política de recursos hídricos implementada pelos governos federal, estadual e municipal está voltada para o aumento da oferta de água potável, por meio da construção de cisternas, barragens, estações de tratamento de águas e perfuração/instalação de poços.
Embora as águas subterrâneas se apresentem como alternativas no suprimento de água potável, algumas restrições são feitas quanto à sua qualidade, pois, em sua maioria, são salobras ou salgadas devido a fatores como a intemperização dos minerais existentes 
nas rochas e as características do solo. Diante dessa realidade, foi dada grande atenção para os programas de dessalinização, o que permitiu a exploração de águas subterrâneas por meio da instalação de dessalinizadores no semiárido brasileiro, com a finalidade de converter água salgada ou salobra em água potável.

O processo de dessalinização produz, por osmose reversa (OR), a partir de água salobra ou salgada, dois tipos de efluentes: água potável e rejeito. $\mathrm{O}$ rejeito é a água concentrada que não passa pelas membranas e carrega consigo a maior parte dos sais dissolvidos na água de alimentação (água bruta). Apesar da melhoria da qualidade de vida de muitas comunidades, o uso de dessalinizadores traz grande preocupação devido à geração do rejeito.

Pessoa (2000) realizou um estudo de impacto ambiental em vinte dessalinizadores instalados no município de Canindé, estado do Ceará, por meio da caracterização do rejeito, levantamento do destino desse subproduto e seu efeito sobre o meio ambiente. Os principais impactos ambientais observados foram: erosão e salinização do solo $(30 \%)$; somente erosão do solo (15\%) e erosão e alteração da flora (10\%); tais impactos seguiram-se a outros, como a salinização da água e a proliferação de microrganismos, algas e insetos. Os métodos atuais de disposição do rejeito são preocupantes, como a injeção em poços, despejo em terrenos, lançamento em lagoas e em outros corpos de água que, certamente, prejudicarão os solos e as plantas, além de contaminar mananciais subterrâneos e superficiais.

Atualmente, o grande desafio é a dessalinização de águas sem agredir o meio ambiente. Por isso, diversos estudos estão sendo direcionados com o objetivo de apontar alternativas de aproveitamento do rejeito.

Para minimizar os possíveis impactos ambientais causados pela dessalinização, o Ministério do Meio Ambiente (MMA) tem desenvolvido açôes para o estudo de alternativas de aproveitamento do rejeito. Os estudos estão centralizados, praticamente, em três linhas de pesquisa: extração de sais minerais por evaporação; formação de meio líquido para o cultivo de tilápias, que são espécies extremamente resistentes a ambientes salinos; e cultivo irrigado com plantas halófilas (a exemplo da Atriplex nummularia), que necessitam de águas com teores salinos elevados para se desenvolver.

A questão ambiental remete de imediato para outra, que se faz presente na qualidade de vida da população. Além da escassez de água, a população que reside distante dos centros urbanos, em sua maioria, não dispõe de água tratada, ficando exposta aos riscos de doenças transmitidas pelas águas. Essas doenças estão presentes, principalmente, em comunidades carentes que não dispõem de qualquer tipo de tratamento de água. Uma pesquisa realizada pela Organização Mundial de Saúde (OMS) entre 1985 e 1986 mostra que cerca de $80 \%$ de todas as doenças humanas estão relacionadas à água não tratada. Quando transmitidas pelas águas, as doenças respondem por, no mínimo, 25 milhôes de mortes a cada ano no Terceiro Mundo. Estudos realizados pelo Fundo das Naçóes Unidas para Infância e Adolescência (Unicef), sobre o fornecimento de água nos países em desenvolvimento, mostram que apenas $51 \%$ das pessoas têm acesso à água potável (Corson, 1996).

Foi com essa preocupação que a Organização Pan-americana de Saúde (OPS) promoveu, em 1982, um programa para incrementar na América Latina, em comunidades não assistidas pelo abastecimento público, o desenvolvimento de equipamentos que viabilizassem a implantação de unidades geradoras de cloro, no mesmo local de utilização. Para tanto, foi implementada a técnica Mixed Oxidant Gases Generated On-site for Disinfection (MOGGOD), que se baseia na eletrólise de uma solução de cloreto de sódio, produzindo in loco misturas de gases oxidantes para a desinfecção de águas.

As vantagens da técnica MOGGOD são vistas pelo baixo custo e facilidade de obtenção da matériaprima $(\mathrm{NaCl})$, tornando-se ideal para atender pequenas comunidades. Ressaltam-se as vantagens em relação à tecnologia convencional, que requer o uso de produtos à base de cloro, os quais, embora eficientes, apresentam desvantagens em face das dificuldades no transporte, armazenamento, acondicionamento, manuseio, dosagem, além dos perigos de toxidez, corrosividade e agressividade ambiental (Bollmann, 1995).

A técnica MOGGOD sofreu alterações, e como inovação tecnológica, foi desenvolvido um novo sistema que produz uma solução de misturas oxidantes com a mesma eficiência dos gases oxidantes. A solução obtida, produto da reação eletrolítica do sal, contém, principalmente, hipoclorito de sódio $(\mathrm{NaOCl})$, além do cloro livre e outros oxidantes. Essa tecnologia é mais vantajosa, visto ser mais conveniente trabalhar com misturas de soluções oxidantes do que com misturas de gases oxidantes (Reiff e Witt, 1995).

Diante das questóes levantadas, buscaram-se, neste trabalho, soluções que minimizem, conjuntamente, os impactos ambientais causados pelo lançamento do rejeito no solo e os problemas gerados em pequenas comunidades pela ausência de água potável. Assim, o objetivo deste trabalho consistiu no estudo do aproveitamento do rejeito, com a finalidade de produzir, pelo processo de eletrólise, solução oxidante para a desinfecção de água.

\section{MATERIAL E MÉTODOS}

Neste trabalho foram pesquisados três tipos de rejeitos de diferentes concentrações de sais. Para facilitar a compreensão dos resultados, principalmente na organização dos dados em tabelas e gráficos, convencionou-se que $o$ rejeito de menor concentração seria denominado de rejeito 1 , o de média de rejeito 2; e o de maior concentração de rejeito 3 .

A amostra do rejeito 1 foi coletado de um dessalinizador instalado no município de Caucaia no estado do Ceará. A água que alimenta o dessalinizador vem de um poço tubular com $40 \mathrm{~m}$ de profundidade e vazão de alimentação de $1.700 \mathrm{~L} / \mathrm{h}$. O dessalinizador produz em média $6.000 \mathrm{~L} /$ dia de rejeito, sendo este jogado em uma lagoa situada, aproximadamente, a $200 \mathrm{~m}$ do poço que alimenta o dessalinizador.

O rejeito 2 é proveniente da localidade Triângulo de Quixadá, município de Chorozinho, estado do Ceará. A água que alimenta o dessalinizador é de um poço tubular com $60 \mathrm{~m}$ de profundidade e vazão de alimentação de $2.200 \mathrm{~L} / \mathrm{h}$. O dessalinizador funciona em média vinte horas por dia, com uma produção de $1.200 \mathrm{~L} / \mathrm{h}$ de rejeito. Esse rejeito é injetado em uma cacimba de $15 \mathrm{~m}$ de profundidade e a $10 \mathrm{~m}$ de distância do poço.

O dessalinizador que produz o rejeito 3 fica instalado na fazenda Lagoa do Serrote, no Km 31 da estrada do Algodão, município de Ocara, região 
Nordeste do estado do Ceará. A água que alimenta o dessalinizador é proveniente de um poço tubular com $60 \mathrm{~m}$ de profundidade e vazão de alimentação de $1.800 \mathrm{~L} / \mathrm{h}$. O dessalinizador funciona em média cinco horas por dia, com uma produção de $1.500 \mathrm{~L} / \mathrm{h}$ de rejeito. $\mathrm{O}$ rejeito é despejado diretamente no solo em buracos de formigueiros.

Foram coletados cerca de $130 \mathrm{~L}$ de cada rejeito e armazenados em recipientes plásticos para a realização dos ensaios de eletrólise. Os ensaios foram realizados em bateladas com cinco repetiçôes para cada rejeito, totalizando 15 ensaios.

Os experimentos foram iniciados com o rejeito 1. Para cada batelada foi colocado 25 litros do rejeito 1 na câmara de recirculação e, logo a seguir, a fonte de corrente do eletrolisador foi ligada à rede elétrica, dando início ao processo de eletrólise. Durante a reação de eletrólise foram monitorados, a cada hora, os seguintes parâmetros: condutividade elétrica, $\mathrm{pH}$, temperatura e cloro total, sendo o tempo total da reação de eletrólise de oito horas. No final da reação foi determinado o cloro ativo, o hipoclorito de sódio $(\mathrm{NaOCl})$ e o cloreto $(\mathrm{Cl})$ remanescente. Para garantir um bom desempenho da célula eletrolítica os eletrodos eram lavados após cada batelada; o ânodo lavado com água e o cátodo com solução de ácido acético comercial $\left(\mathrm{CH}_{3} \mathrm{COOH}\right)$ para a retirada das incrustaçôes. Para os rejeitos 2 e 3 foram seguidos o mesmo procedimento descrito para o rejeito 1 .

Para o desenvolvimento dos experimentos foi utilizado um eletrolisador de fabricação nacional, modelo GE-25, como mostra a figura 1, que produz, em oito horas, $25 \mathrm{~L}$ da solução oxidante. $\mathrm{O}$ equipamento possui uma fonte de corrente com alimentação de 220 V/2A e saída de 6,5 V/25A; uma câmara de recirculação (reator) de material resistente às condiçōes termoquímicas da reação eletrolítica; uma célula eletrolítica constituída por um par de eletrodos, formado por duas placas paralelas, com espessuras de $2 \mathrm{~mm}$ cada uma e áreas de $48 \mathrm{~cm}^{2}$, com $1.530 \mathrm{~cm}^{3}$ de volume livre, em que ocorre a reação de transformação do rejeito em solução oxidante; as placas são de titâneo, sendo uma revestida com rutênio (ânodo) e outra sem revestimento (cátodo); dois cabos de alimentação, um vermelho conectado ao eletrodo positivo, e o cabo preto, ao eletrodo negativo.

As águas brutas provenientes dos poços e os rejeitos foram analisados quanto aos parâmetros: $\mathrm{pH}$, temperatura, turbidez, cor aparente, condutividade elétrica, alcalinidade total, dureza total, matéria orgânica, sólidos dissolvidos, sólidos totais, cálcio, magnésio, sódio, potássio, ferro, cloreto, sulfato, nitrato, coliformes totais e coliformes fecais. Foram seguidos padróes de potabilidade estabelecidos pela Portaria no 518 (BRASIL, 2004) e de acordo com a metodologia recomendada por Eaton $e t$ al (1999), com exceção das análises da matéria orgânica, cor aparente e cloro total. A matéria orgânica foi determinada segundo Rodier (1990). Para determinar o cloro total, empregou-se o método reflectométrico por meio de um colorímetro portátil, utilizando cubeta com percurso ótico de $1,0 \mathrm{~cm}$ e reagente DPD (N,N-dietil-P-Fenilenodiamino). A escolha desse método justifica-se pelo fato de o equipamento apresentar alta sensibilidade, obtendo-se valor de cloro em baixas concentrações (de $0,05 \mathrm{mg}$ a 2,00 $\mathrm{mg} \mathrm{de} \mathrm{Cl}_{2} / \mathrm{L}$ ).

Os dados foram analisados através de gráficos, tabelas e intervalos de confiança. Foi utilizada a técnica de Análise

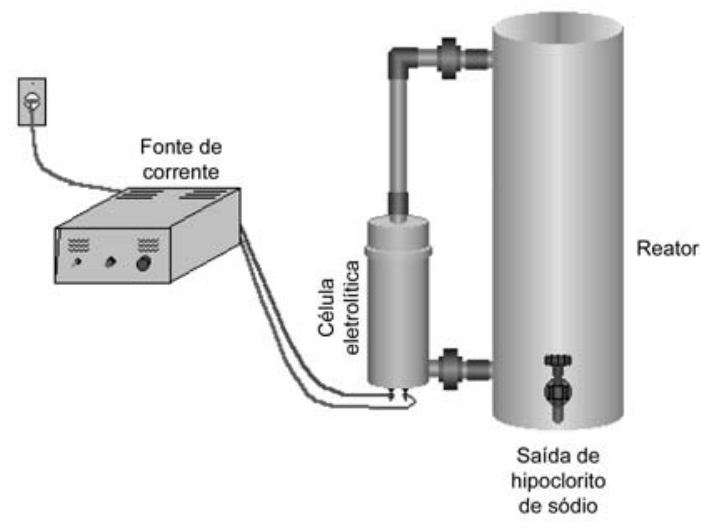

de Variância para fazer a comparação de cada parâmetro, entre os rejeitos utilizados ao longo do tempo. Utilizou-se o teste de Tukey para comparação de médias.

\section{RESULTADOS E DISCUSSÃO}

As águas brutas e dos rejeitos, conforme se observa nas tabelas $1,2 \mathrm{e}$ 3 , apresentaram contaminação por coliformes totais e fecais com maior índice de contaminação para a água bruta e rejeito 3. Observa-se, ainda, tanto para as águas brutas como para os rejeitos que os parâmetros dureza total, sólidos totais, sódio e cloreto encontram-se bastantes elevados e fora dos padrōes recomendados pela Portaria 518. Maior concentração de cloreto foi registrado para o rejeito 3 , seguido do rejeito 2 e por último, o rejeito 1 .

Os resultados mostrados nas figuras de 2 a 8 , representam para cada parâmetro a média de cinco repetiçôes dos ensaios de eletrólise, realizados para cada rejeito.

A figura 2 mostra a variação do $\mathrm{pH}$, com uma tendência de crescimento, ao longo do tempo da reação de eletrólise dos rejeitos 1,2 e 3 , chegando atingir valores superiores a 8 no caso dos rejeitos 1 e 3 . O crescimento pode ser justificado pela ocorrência das reaçôes de oxirredução e formação de produtos alcalinos, como o $\mathrm{NaOCl}$. No rejeito 3 percebe-se um comportamento instável do $\mathrm{pH}$ a partir da primeira hora de reação, no entanto foi na reação do rejeito 2 que se observou, no tempo de seis horas, uma queda acentuada do $\mathrm{pH}$. As variaçōes podem ter sido causada por oscilações no pH-metro ou, até mesmo, pela presença de espécies químicas de caráter ácido nos rejeitos.

$\mathrm{Na}$ análise estatística, pôde-se observar que para os resultados de $\mathrm{pH}$ apresentados:

- não houve diferença significativa $(\mathrm{p}=0,491)$ do $\mathrm{pH}$ entre os rejeitos utilizados;

- houve efeito significativo $(\mathrm{p}<0,05)$ do tempo no comportamento do $\mathrm{pH}$. O parâmetro $\mathrm{pH}$ tem comportamento linear crescente em função do tempo $(\mathrm{p}<0,05)$, com modelo estimado dado por: $\mathrm{pH}=7,927+0,025^{*}$ tempo.

- não houve diferença significativa $(\mathrm{p}=0,06)$ do $\mathrm{pH}$ na combinação dos efeitos do rejeito e do tempo.

Figura I - Eletrolisador e fonte de corrente 
Tabela I - Características da água bruta e do rejeito I

\begin{tabular}{|c|c|c|}
\hline Parâmetro & Água bruta & Rejeito 1 \\
\hline $\mathrm{pH}$ a $25^{\circ} \mathrm{C}$ & 6,88 & 7,2 \\
\hline Temperatura $\left({ }^{\circ} \mathrm{C}\right)$ & 28 & 27 \\
\hline Turbidez (uT) & 0,60 & 0,95 \\
\hline Cor aparente $(\mathrm{uH})$ & 6 & 5 \\
\hline Condutividade elétrica $(\mu \mathrm{S} / \mathrm{cm})$ & 3.800 & 5.400 \\
\hline Alcalinidade total $\left(\mathrm{mg} \mathrm{CaCO}_{3} / \mathrm{L}\right)$ & 240,6 & 245,5 \\
\hline Dureza total $\left(\mathrm{mg} \mathrm{CaCO}_{3} / \mathrm{L}\right)$ & $1.325,5$ & 1.386 \\
\hline Matéria orgânica (mg $\mathrm{O}_{2}$ cons./L) & 7,9 & 7,1 \\
\hline Sólidos dissolvidos (mg/L) & $2.750,0$ & 2.830 \\
\hline Sólidos totais $(\mathrm{mg} / \mathrm{L})$ & $2.980,0$ & 3.010 \\
\hline Cálcio (mg Ca/L) & 160,0 & 165,6 \\
\hline Magnésio (mg Mg/L) & 224,9 & 236,2 \\
\hline Sódio $(\mathrm{mg} \mathrm{Na} / \mathrm{L})$ & 480,0 & 488,0 \\
\hline Potássio (mg K/L) & 41,0 & 38,6 \\
\hline Ferro (mg Fe/L) & 0,1 & $<0,1$ \\
\hline Cloreto (mg Cl-/L) & $1.544,8$ & 1.678 \\
\hline Sulfato $\left(\mathrm{mg} \mathrm{SO}_{4}^{2-/ \mathrm{L})}\right.$ & 3,8 & 3,3 \\
\hline Nitrato $\left(\mathrm{mg} \mathrm{N}-\mathrm{NO}_{3}^{-} / \mathrm{L}\right)$ & $<1,0$ & 0,6 \\
\hline Coliformes totais (NMP/100ml) & 95 & $4,6 \times 10^{2}$ \\
\hline Coliformes fecais (NMP/100ml) & $<3,0$ & $<3,0$ \\
\hline
\end{tabular}

Tabela 2 - Características da água bruta e do rejeito 2

\begin{tabular}{|c|c|c|}
\hline Parâmetro & Água bruta & Rejeito 2 \\
\hline $\mathrm{pH}$ a $25^{\circ} \mathrm{C}$ & 8,0 & 8,3 \\
\hline Temperatura $\left({ }^{\circ} \mathrm{C}\right)$ & 30 & 27 \\
\hline Turbidez (uT) & 0,3 & 0,40 \\
\hline Cor aparente $(\mathrm{uH})$ & 7 & 9 \\
\hline Condutividade elétrica $(\mu \mathrm{S} / \mathrm{cm})$ & 8.990 & 13.000 \\
\hline Alcalinidade total $\left(\mathrm{mg} \mathrm{CaCO}_{3} / \mathrm{L}\right)$ & 84,6 & 139,3 \\
\hline Dureza total $\left(\mathrm{mg} \mathrm{CaCO}_{3} / \mathrm{L}\right)$ & $2.685,3$ & 4.562 \\
\hline Matéria orgânica (mg $\mathrm{O}_{2}$ cons./L) & 3,9 & 5,6 \\
\hline Sólidos dissolvidos (mg/L) & $5.806,0$ & 10.738 \\
\hline Sólidos totais $(\mathrm{mg} / \mathrm{L})$ & $5.988,0$ & 11.718 \\
\hline Cálcio (mg Ca/L) & 148,2 & 261,7 \\
\hline Magnésio (mg Mg/L) & 562,5 & 949,5 \\
\hline Sódio (mg Na/L) & 780,0 & $1.440,0$ \\
\hline Potássio (mg K/L) & 66,9 & 123,2 \\
\hline Ferro (mg Fe/L) & $<0,1$ & $<0,1$ \\
\hline Cloreto (mg Cl-/L) & $3.101,3$ & 5.458 \\
\hline Sulfato (mg SO $\left.{ }_{4}^{2-/ L}\right)$ & 3,8 & 5,9 \\
\hline Nitrato $\left(\mathrm{mg} \mathrm{N}-\mathrm{NO}_{3}^{-} / \mathrm{L}\right)$ & 2,2 & 3,3 \\
\hline Coliformes totais (NMP/100ml) & 3,6 & $<3,0$ \\
\hline Coliformes fecais (NMP/100ml) & $<3,0$ & $<3,0$ \\
\hline
\end{tabular}


Tabela 3 - Características da água bruta e do rejeito 3

\begin{tabular}{|c|c|c|}
\hline Parâmetro & Água bruta & Rejeito 3 \\
\hline $\mathrm{pH}$ a $25^{\circ} \mathrm{C}$ & 7,4 & 7,7 \\
\hline Temperatura $\left({ }^{\circ} \mathrm{C}\right)$ & 27 & 27 \\
\hline Turbidez (uT) & 1,1 & 0,70 \\
\hline Cor aparente $(\mathrm{uH})$ & 15 & 12 \\
\hline Condutividade elétrica $(\mu \mathrm{S} / \mathrm{cm})$ & 22.430 & 24.500 \\
\hline Alcalinidade total $\left(\mathrm{mg} \mathrm{CaCO}_{3} / \mathrm{L}\right)$ & 55,7 & 55,7 \\
\hline Dureza total $\left(\mathrm{mg} \mathrm{CaCO}_{3} / \mathrm{L}\right)$ & $9.716,3$ & 10.977 \\
\hline Matéria orgânica ( $\mathrm{mg} \mathrm{O}_{2}$ cons./L) & 10,3 & 9,2 \\
\hline Sólidos dissolvidos (mg/L) & $16.822,0$ & 19.310 \\
\hline Sólidos totais (mg/L) & $17.086,0$ & 19.494 \\
\hline Cálcio (mg Ca/L) & $1.224,7$ & $1.407,4$ \\
\hline Magnésio (mg Mg/L) & $1.617,0$ & $1.812,0$ \\
\hline Sódio (mg Na/L) & $1.220,0$ & $1.480,0$ \\
\hline Potássio (mg K/L) & 162,4 & 251,0 \\
\hline Ferro $(\mathrm{mg} \mathrm{Fe} / \mathrm{L})$ & 0,2 & 0,1 \\
\hline Cloreto (mg Cl-/L) & $8.835,4$ & 10.200 \\
\hline Sulfato $\left(\mathrm{mg} \mathrm{SO}_{4}^{2-/ L}\right)$ & 58,8 & 71,1 \\
\hline Nitrato $\left(\mathrm{mg} \mathrm{N}-\mathrm{NO}_{3}^{-} / \mathrm{L}\right)$ & 1,7 & 2,0 \\
\hline Coliformes totais (NMP/100ml) & $1,1 \times 10^{3}$ & $7,8 \times 10^{2}$ \\
\hline Coliformes fecais (NMP/100ml) & 46,3 & 69,7 \\
\hline
\end{tabular}
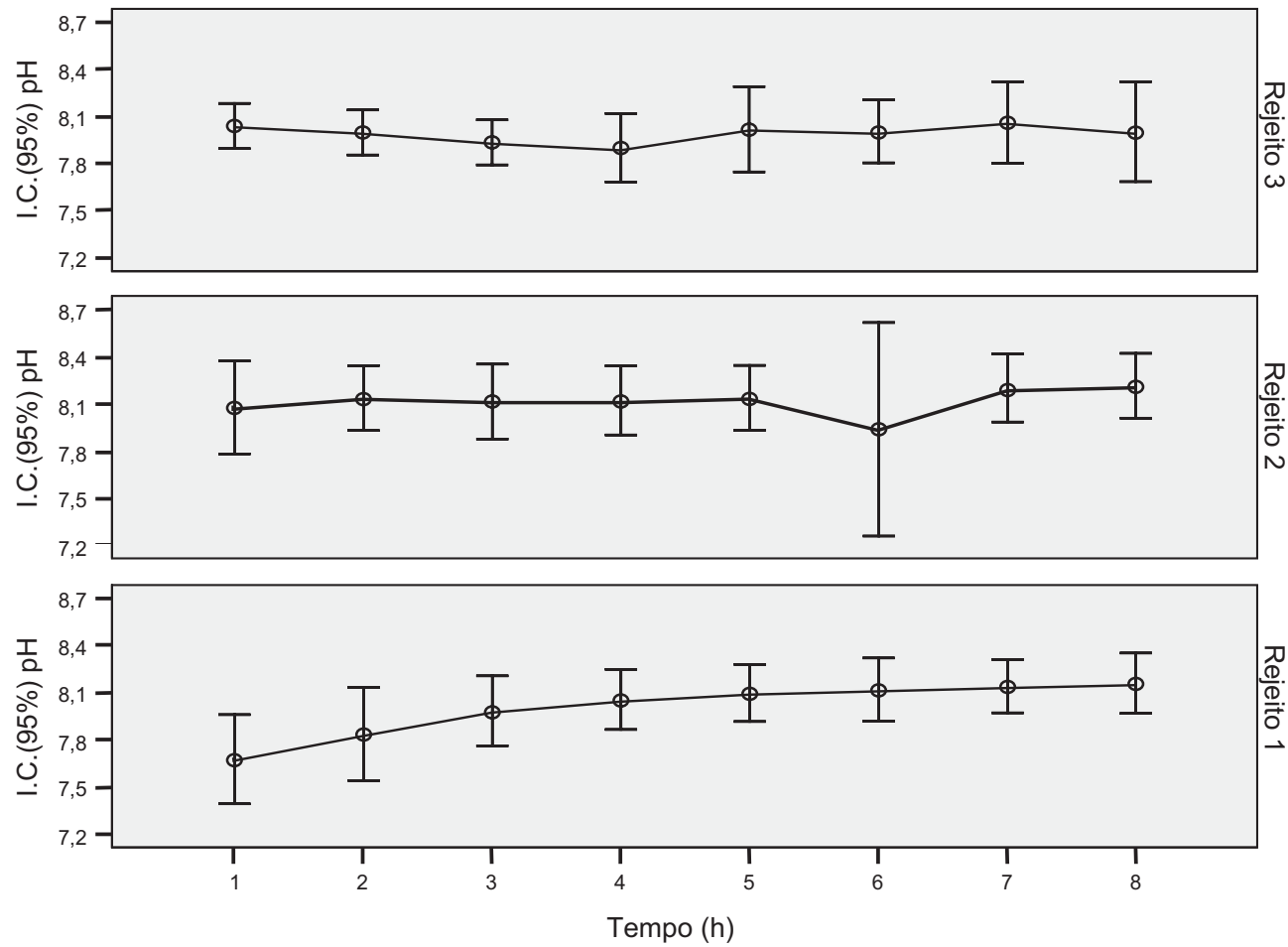

Figura 2 - Intervalo de confiança $(0,95)$ para o parâmetro de pH em cada rejeito ao longo do tempo 
Um mesmo comportamento da temperatura ao longo do tempo da reação de eletrólise pode ser visualizado através da figura 3, sendo que o rejeito 3 atingiu maiores temperaturas. Tal fato deve-se por esse apresentar maior concentração de sais do que os rejeitos 1 e 2 .

Outro aspecto observado, na figura 3, além da semelhança entre as curvas de temperatura é a defasagem praticamente constante entre elas. Segundo análise estatística da temperatura, houve:

- diferença significativa $(\mathrm{p}<0,01)$ da temperatura entre os rejeitos utilizados;

- efeito significativo $(\mathrm{p}<0,01)$ do tempo no comportamento da temperatura. No rejeito 1 o modelo linear foi significativo $(\mathrm{p}<0,01)$, dado por: temperatura $=27,286+0,414^{*}$ tempo; no rejeito 2 o modelo linear foi significativo $(\mathrm{p}<0,01)$, dado por: temperatura $=29,843+0,9745^{*}$ tempo e no rejeito 3 o modelo linear foi significativo $(\mathrm{p}<0,01)$, dado por: temperatura $=$ $29,836+1,298^{*}$ tempo.

- diferença significativa $(\mathrm{p}<0,01)$ da temperatura na combinação dos efeitos do rejeito e do tempo.

A variação média da condutividade elétrica durante a eletrólise do rejeito 1 foi de $4.988 \mu \mathrm{S} / \mathrm{cm}$ a $5.084 \mu \mathrm{S} / \mathrm{cm}$; com o rejeito 2 , de $13.318 \mu \mathrm{S} / \mathrm{cm}$ a $13.416 \mu \mathrm{S} / \mathrm{cm}$; e com o rejeito 3 , de
$25.116 \mu \mathrm{S} / \mathrm{cm}$ a $25.312 \mu \mathrm{S} / \mathrm{cm}$.

A análise da condutividade elétrica está representada na figura 4. Constatou-se uma estabilidade da condutividade para os rejeitos 1 e 2 logo após as primeiras horas de funcionamento do eletrolisador. Para o rejeito 3 observouse um comportamento instável nas primeiras horas da reação, e somente a partir da sétima hora ocorreu um comportamento mais estável. Houve diferença significativa $(\mathrm{p}<0,01)$ da condutividade elétrica entre os três rejeitos utilizados, que apresentaram, segundo o teste de Tukey a um nível de 5\% de significância, diferenças significativas entre suas médias, sendo que o rejeito 3 apresentou maior média e o rejeito 1 a menor média. Não houve:

- efeito significativo $(\mathrm{p}=0,391)$ do tempo no comportamento da condutividade elétrica;

- diferença significativa $(\mathrm{p}=0,463)$ da condutividade elétrica na combinação dos efeitos do rejeito e do tempo.

Quanto à produção do cloro total, a figura 5 mostra que para todos os rejeitos há uma tendência de crescimento nos tempos maiores de operação da célula eletrolítica. Um mesmo comportamento da produção de cloro, ao longo do tempo da reação de eletrólise, pode ser visualizado, com maior produção de cloro para o rejeito 3. Tal fato está associado à maior concentração de sais do que nos rejeitos 1 e 2 . A concentração de cloreto no rejeito 1 foi de $1.678 \mathrm{mg}$ $\mathrm{Cl}^{-} / \mathrm{L}$, no rejeito $2 \mathrm{de} 5.458 \mathrm{mg} \mathrm{Cl} / \mathrm{L} \mathrm{e}$ no rejeito 3 de $10.200 \mathrm{mg} \mathrm{de} \mathrm{Cl} / \mathrm{L}$.

Os valores médios de produção de cloro total, no final das oito horas, foi de $705 \mathrm{mg} / \mathrm{L}, 3.085 \mathrm{mg} / \mathrm{L}$ e $3.715 \mathrm{mg} / \mathrm{L}$ para os rejeitos 1,2 e 3 , respectivamente, para um mesmo tempo de reação, como esperado. $\mathrm{Na}$ análise estatística houve:

- diferença significativa $(\mathrm{p}<0,01)$ do cloro total entre os rejeitos utilizados;

- efeito significativo $(\mathrm{p}<0,01)$ do tempo no comportamento do cloro total. No rejeito 1 o modelo linear foi significativo $(\mathrm{p}<0,01)$, dado por: cloro total $=33,966+83,299 *$ tempo; no rejeito 2 o modelo linear foi significativo $(\mathrm{p}<0,01)$, dado por: cloro total $=-213,768+404,476^{*}$ tempo e no rejeito 3 o modelo linear foi significativo $(\mathrm{p}<0,01)$, dado por: cloro total $=167,929+473,488^{*}$ tempo.

- diferença significativa $(\mathrm{p}<0,01)$ do cloro total na combinação dos efeitos do rejeito e do tempo.

Os compostos cloro ativo e $\mathrm{NaOCl}$ das soluções oxidantes obtidos com os rejeitos foram determinados no final da eletrólise. Assim, como observado no cloro total, o maior teor de cloro ativo médio foi de $0,10 \%$, $0,24 \%$ e $0,27 \% \mathrm{~m} / \mathrm{m}$ para as soluçóes oxidantes obtidas dos rejeitos 1, 2 e 3 , respectivamente; e o menor teor foi o da solução oxidante do rejeito 1

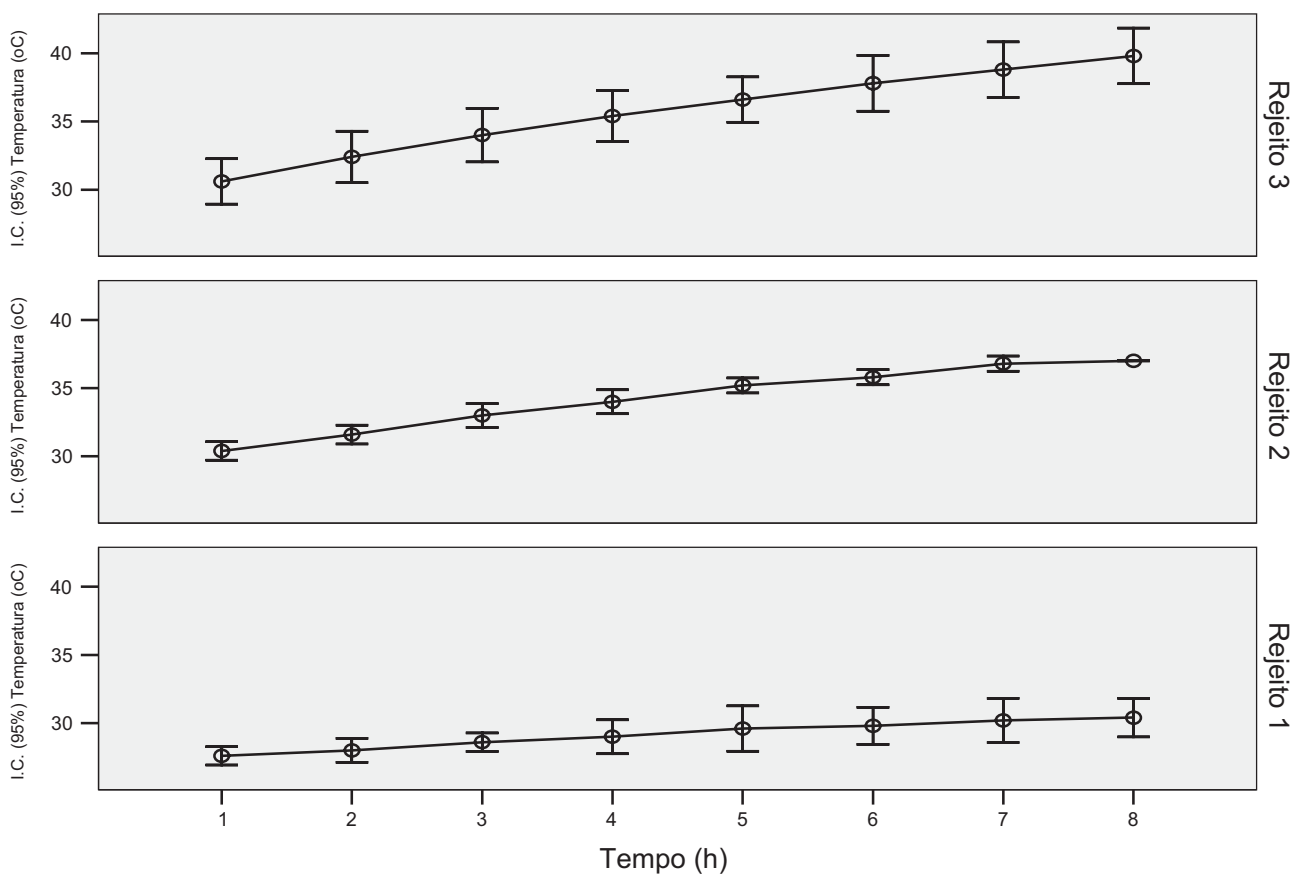

Figura 3 - Intervalo de confiança $(0,95)$ para o parâmetro de temperatura em cada rejeito ao longo do tempo 

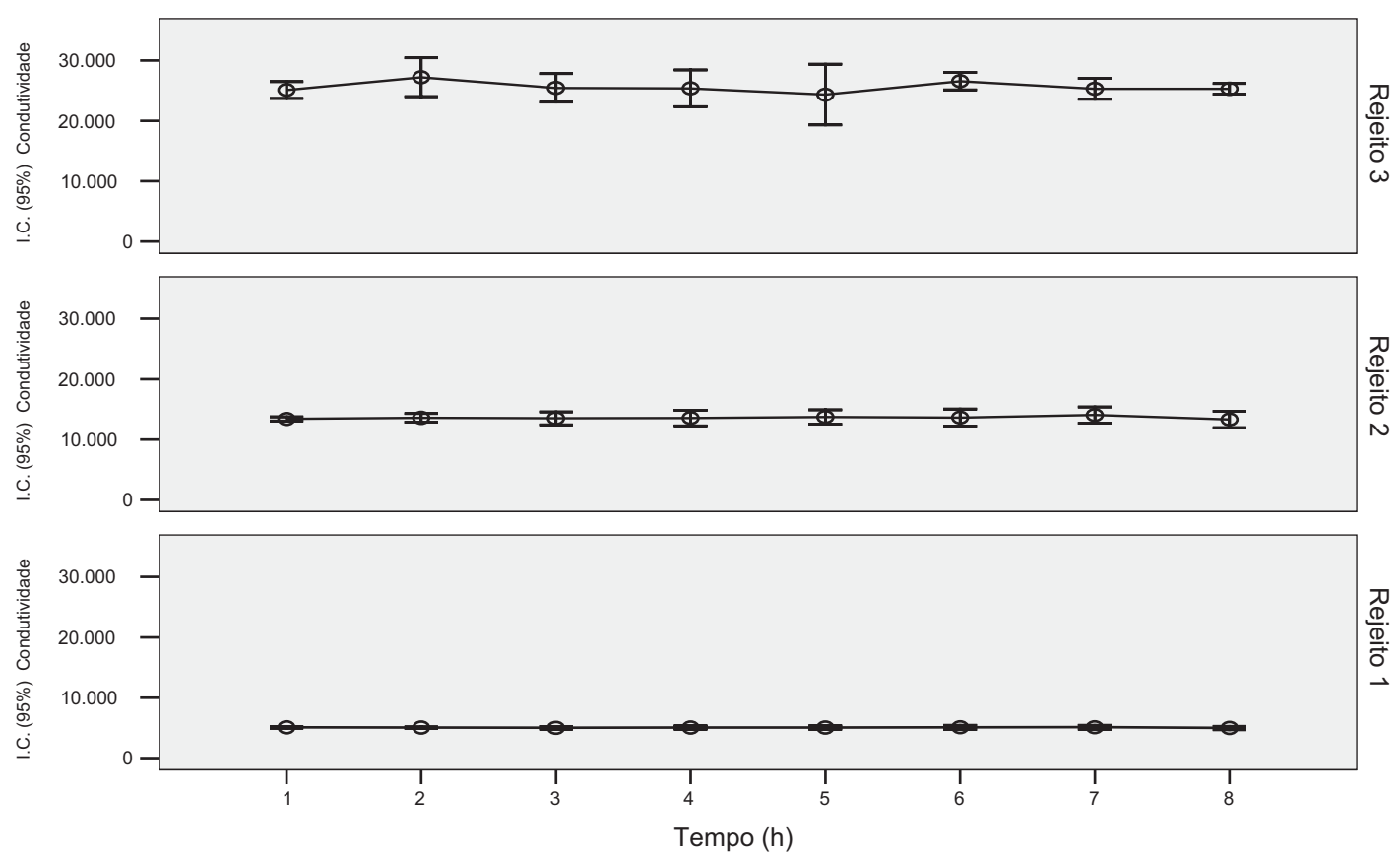

Figura 4 - Intervalo de confiança $(0,95)$ para o parâmetro de condutividade elétrica em cada rejeito ao longo do tempo

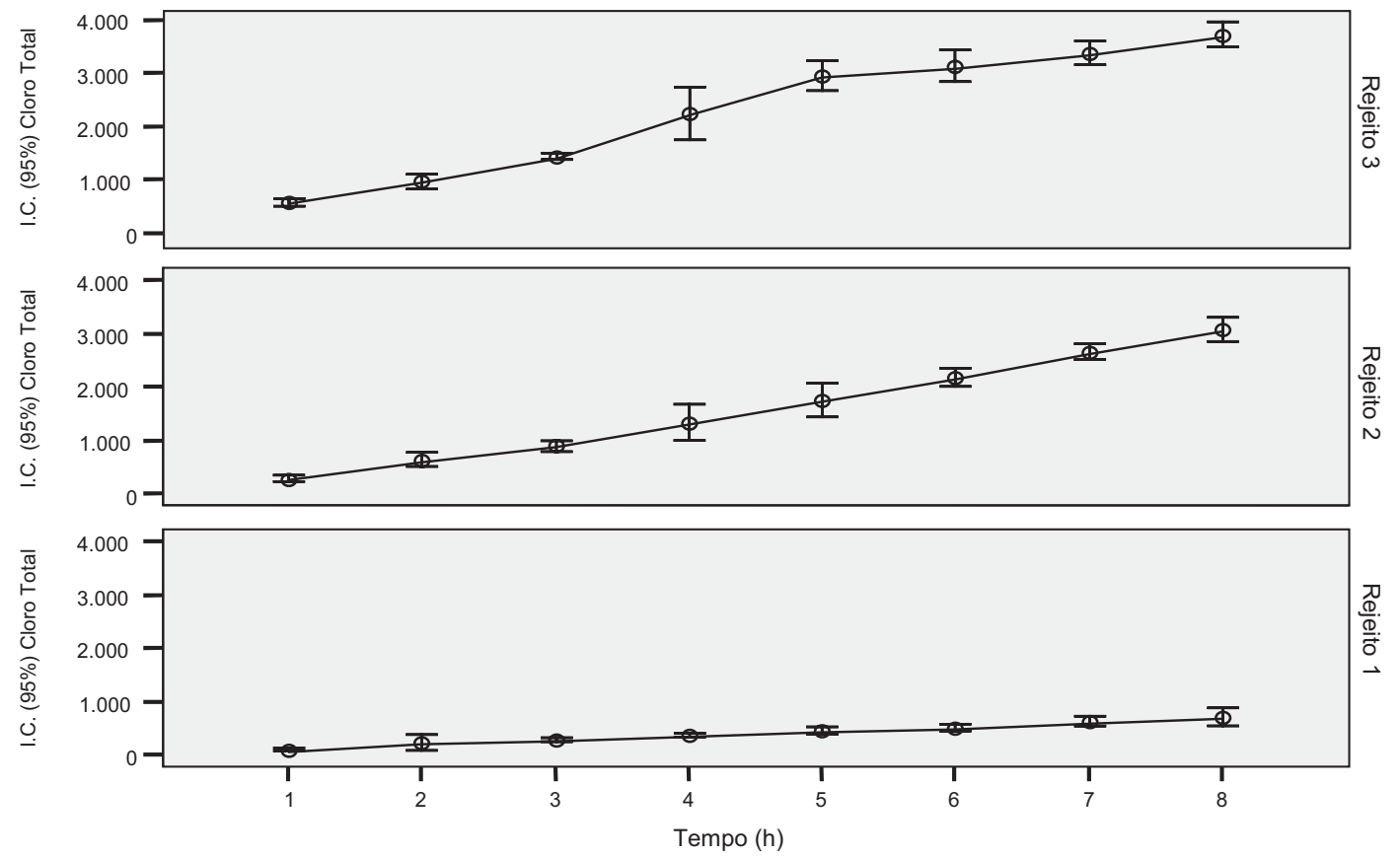

Figura 5 - Intervalo de confiança $(0,95)$ para o parâmetro de cloro total em cada rejeito ao longo do tempo

A figura 6 representa o valor médio de cloro ativo e $\mathrm{NaOCl}$ para as soluções oxidantes obtidas dos rejeitos 1,2 e 3. Na escala real, conforme se constatou in loco, a unidade de eletrólise da Companhia de Água e Esgoto do Ceará (CAGECE) produz solução oxidante com teor de cloro ativo igual a $0,5 \% \mathrm{~m} / \mathrm{m}$, a partir de uma solução de sal com $1,42 \% \mathrm{~m} / \mathrm{m}$ de concentração, ou seja, $14.200 \mathrm{mg} \mathrm{de} \mathrm{Cl} / \mathrm{L}$. Solsona e Méndez (2002) relatam que o $\mathrm{NaOCl}$ produzido por eletrólise deve apresentar teor de cloro ativo de $0,1 \%$ a $0,6 \%$.

Com a produção de $25 \mathrm{~L}$ da solução oxidante obtida dos rejeitos 1,2 e 3 , com a dosagem de $5,0 \mathrm{mg} \mathrm{de} \mathrm{Cl}_{2} / \mathrm{L}$, por exemplo, é possível desinfetar, em média, $5 \mathrm{~m}^{3}, 12 \mathrm{~m}^{3}$ e $13,5 \mathrm{~m}^{3}$ de água, respectivamente.
A solução oxidante gerada com o rejeito 1 apresentava uma coloração avermelhada, característica da oxidação de ferro ou manganês presente no rejeito. $\mathrm{O}$ teor de ferro no rejeito 1 foi $<0,1 \mathrm{mg}$ de $\mathrm{Fe} / \mathrm{L}$ e o de manganês foi igual a $0,70 \mathrm{mg}$ de $\mathrm{Mn} / \mathrm{L}$. A figura 7 mostra o precipitado e a sedimentação dos sais remanescentes presentes na solução oxidante, gerada do rejeito 3 , 
após oito horas de eletrólise. Os sais precipitados nas soluçóes oxidantes de todos os rejeitos foram caracterizados, indicando a presença de sulfato de magnésio $\left(\mathrm{CaSO}_{4}\right)$, sulfato de cálcio $\left(\mathrm{CaSO}_{4}\right)$, cloreto de sódio $(\mathrm{NaCl})$, cloreto de magnésio $\left(\mathrm{MgCl}_{2}\right)$ e cloreto de cálcio $\left(\mathrm{CaCl}_{2}\right)$.

A figura 8 mostra o percentual médio de $\mathrm{Cl}^{-}$remanescente para as soluçōes oxidantes geradas a partir dos rejeitos. Nota-se, que o maior teor de $\mathrm{Cl}^{-}$foi registrado para a solução oxidante do rejeito 1 , seguida da solução obtida a partir do rejeito 2 e, por último, a solução oxidante obtida a partir do rejeito 3 , com pequenas diferenças entre eles. Luca e Santanna (2000) observaram que cerca de $85 \%$ do $\mathrm{Cl}^{-}$inicial da salmoura utilizada permaneciam como tal no final do processo de eletrólise. Da mesma forma, o sistema operado pela CAGECE produz uma solução oxidante com $75 \%$ de $\mathrm{Cl}^{-}$remanescen- te. Supondo uma dosagem de 5,0 mg de $\mathrm{Cl}_{2} / \mathrm{L}$ da solução oxidante gerada a partir do rejeito 3, por exemplo, seriam adicionados $8,5 \mathrm{mg} \mathrm{de} \mathrm{Cl}^{-} / \mathrm{L}$ à água tratada.

A figura 9 faz um demonstrativo da média do comportamento da corrente durante o tempo da reação de eletrólise do rejeito 1 . Pôde-se observar que ocorre um acréscimo de apenas 7,3\% entre a corrente inicial do processo até a seu término, considerando praticamente

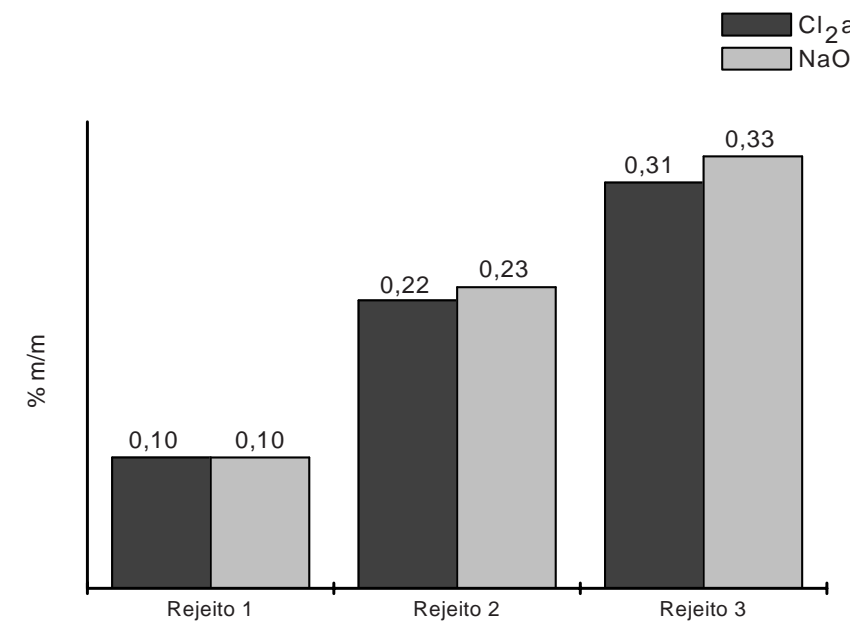

Figura 6 - Produção média de cloro gerado a partir dos rejeitos, no final da reação de eletrólise
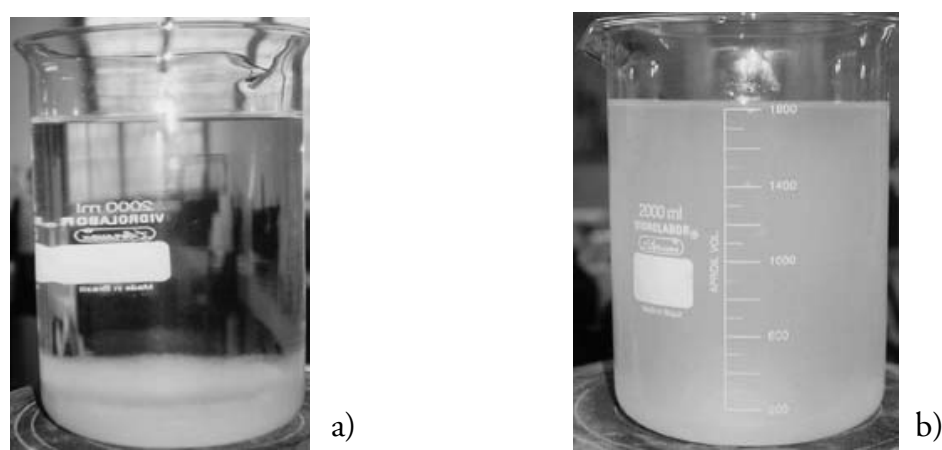

Figura 7 - Solução oxidante gerada a partir do rejeito 3; a) precipitação em solução; b) sedimentação

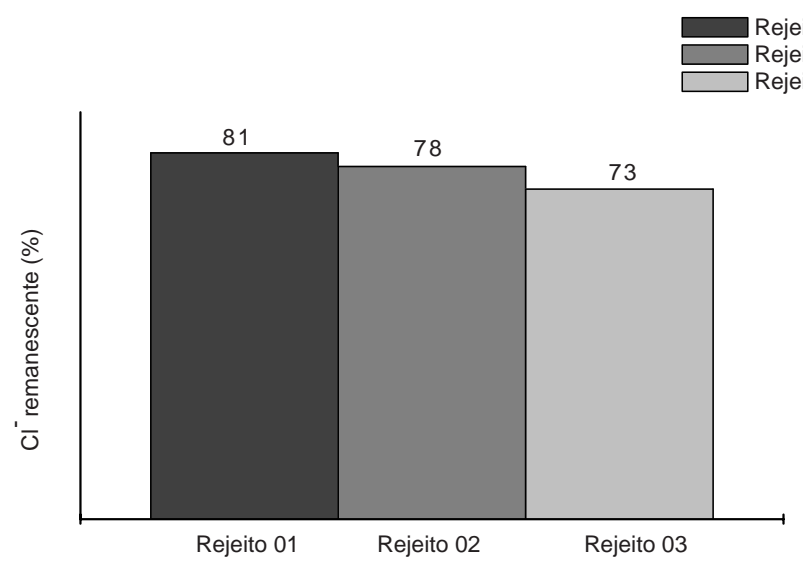

Figura 8 - Média do cloreto remanescente da reação de eletrólise 


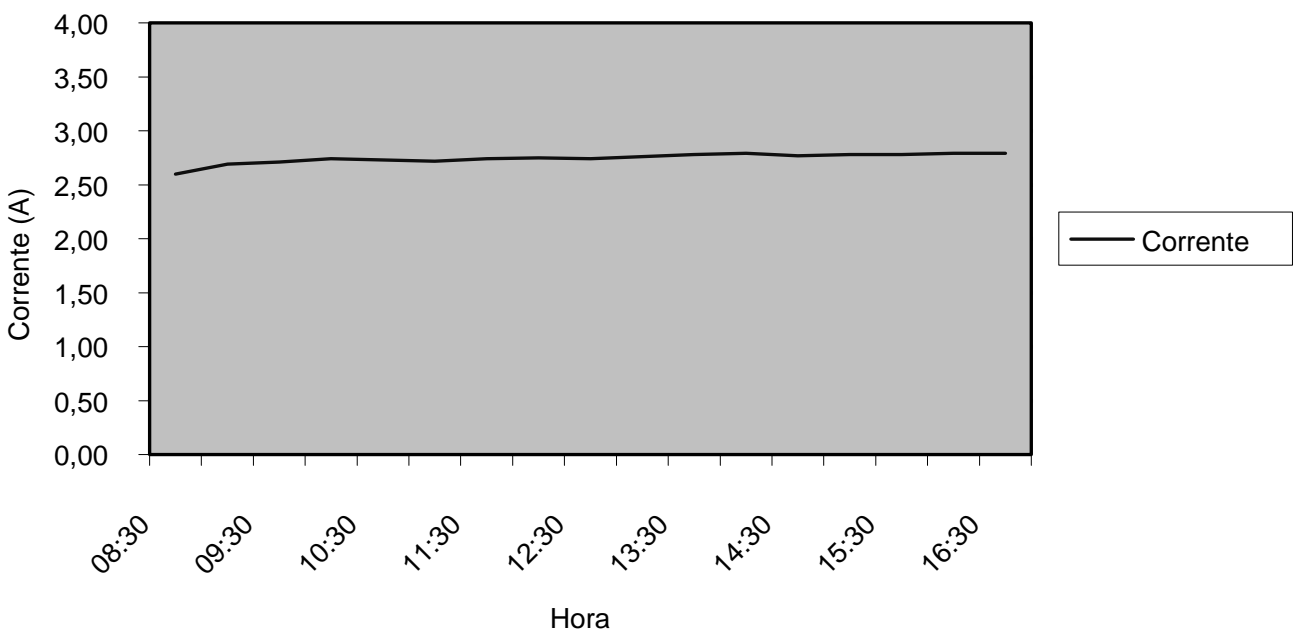

Figura 9 - Fluxo de corrente no processo

invariável. Com isso, concluiu-se que o consumo de energia durante todo o processo de eletrólise é constante.

\section{CONCLUSÕES E RECOMENDAÇỖES}

A análise estatística dos resultados obtidos dos ensaios de eletrólise mostrou um nível de confiança de 95\% para todos os parâmetros estudados. Entre os rejeitos estudados não houve, para o $\mathrm{pH}$, diferença significativa. $\mathrm{Na}$ combinação dos efeitos do rejeito e do tempo, também não houve diferença significativa do $\mathrm{pH}$, enquanto que para a temperatura, condutividade e cloro total houve diferença significativa, na combinação dos efeitos do rejeito e do tempo.

Ao longo do tempo de eletrólise, observou-se o mesmo comportamento de temperatura entre os rejeitos, embora o rejeito 3 tenha atingido maiores temperaturas.

Observou-se que o comportamento de produção de cloro total, ao longo do tempo de reação, foi o mesmo para todos os rejeitos, sendo que o rejeito 3 apresentou maior potencial de produção de cloro por ser um rejeito com maior concentração de sais. $\mathrm{Na}$ análise estatística houve diferença significativa do cloro total entre os rejeitos utilizados e efeito significativo do tempo no comportamento do cloro total.

Recomendam-se pesquisas futuras, em escala de laboratório e piloto, no intuito de investigar a possibilidade de uso da solução oxidante, obtida a partir de rejeito, na desinfecção de água para uso humano. É preciso investigar a formação de outras espécies oxidantes, como suas proporçóes e acompanhamento dos subprodutos gerados ao longo do tempo da reação de eletrólise. Além disso, recomenda-se a realização de pesquisa para a caracterização de todos os sais presentes no rejeito, bem como as conseqüências de seus usos; investigar a presença de metais, assim como sua influência no processo de eletrólise; desenvolver estudo de viabilidade técnico-econômica, comparando o sistema de desinfecção de água com solução oxidante, produzida in loco, pelo processo de eletrólise, a partir de rejeito, com a tecnologia convencional.

Considerando que no processo de eletrólise somente $20 \%$ dos sais são transformados em solução oxidante, recomenda-se um estudo aprofundado de caracterização e utilização dos sais remanescentes. Mesmo assim, ressaltase a vantagem desse processo, visto que a transformação do rejeito em solução oxidante resultará na concentração do sal, evitando o seu contato direto com o solo. Sugere-se o estudo da viabilidade de utilização desses sais para o consumo humano e animal, ou para outros setores, principalmente pela predominância do $\mathrm{NaCl}$.

Independente dessas investigações, a solução oxidante pode ser utilizada na desinfecção de ambientes domésticos e públicos, por exemplo, na lavagem de prédios, escolas, fábricas, calçadas, banheiros e tratamento de esgotos.

Ressalta-se que a prática do uso de rejeitos de dessalinizadores minimiza os impactos ambientais, principalmente no que se refere à salinização do solo e contaminação das águas. Assim, defende-se a implantação de programas governamentais com a finalidade de incentivar todas as formas de pesquisas que visem encontrar alternativas de aproveitamento de rejeito de dessalinizadores.

\section{REFERÊNCIAS}

ASSOCIAÇÃO BRASILEIRA DE NORMAS TÉCNICAS. NBR 9425: solução de hipoclorito de sódio: determinação do teor de cloro ativo pelo método volumétrico. Rio de Janeiro, 3 p. 1986. BOLLMANN, H.A. Desenvolvimento de um equipamento simplificado de desinfecção de águas de abastecimento público pela geração de gases oxidantes produzidos no local. In: $18^{\circ}$ CONGRESSO BRASILEIRO DE ENGENHARIA SANITÁRIA AMBIENTAL. Salvador. ABES 1995.

BRASIL. Ministério da Saúde. Portaria $n^{\circ} 518$, de 25 de março de 2004. Estabelece os procedimentos e responsabilidades relativos ao controle e vigilância da qualidade da água para consumo humano e seu padrão de potabilidade, e dá outras providências. Diário Oficial [da] República Federativa do Brasil, Brasília, DF, 26 mar. 2004. Disponível em: <http://www. anvisa.gov.br/legis/portarias>. Acesso em: 20 mar. 2004.

CORSON, W.H. Manual Global de Ecologia: o que você pode fazer a respeito da crise do meio ambiente. 2. ed. Tradução Alexandre Gomes Camaru. São Paulo. Ed. Augustus, p 412. 1996.

EATON, A.D.; CLESCERI, L.S.; GREENBERG, A.E. Standard methods for the examination of water and wastewater. 20 ed. Washington. Ed. A.P.H.A.I A.W.W.A./W.E.F., CD-ROM. 1999.

LUCA, S.J.; SANTANNA, M.A. Hipoclorito gerado eletroliticamente in loco: subprodutos $e$ avaliação de sua capacidade desinfetante no tratamento de águas. In: XXVII CONGRESSO INTERAMERICANO DE ENGENHARIA SANITÁRIA E AMBIENTAL, Porto Alegre. Anais. ABES, Ref. II-018. 2000.

MONTGOMERY, D.C. Designs and Analysis of Experiments. 3 ed. New York. Ed. John Wiley, 649p. 1991.

PAIXĀO, K.V.; DELFORGE, J.L.; BRANDÃO, C.C.S. Avaliação de um equipamento de geração de misturas oxidantes na inativação de patogênicos, utilizando, como indicadores, 
coliformes e colifagos In: XXVII CONGRESSO INTERAMERICANO DE ENGENHARIA SANITÁRIA E AMBIENTAL, Porto Alegre. Anais. ABES, Ref. II-016. 2000.

PESSOA, L.C.C. Análise do desempenho e do impacto ambiental de dessalinizadores por osmose reversa instalados no interior do Ceará. Dissertação (Mestrado), Departamento de Engenharia Hidráulica e Ambiental, Universidade Federal do Ceará. Fortaleza, 159 f.

REIFF, F.M.; WITT, V.M. Manual de desinfección: guias para la seleccion y aplication de tecnologias de desinfeccion del agua para consumo humano en pueblos pequeños y comunidades rurales en America Latina y el Caribe. Washington. Ed. OPS, Série Técnica no 30. 227 p. 1995.

RODIER, J. Análisis de las aguas: aguas naturales, aguas residuales, agua de mar. Barcelona. Ed. Omega, 1059 p. 1990.

SOARES, J.B.; MAIA, A.C.F. Água: microbiologia e tratamento. Fortaleza. Ed. UFC, 206 p. 1999.

SOLSONA, F.; MÉNDEZ, J.P. Desinfección de aguas. Lima Ed. OPS/CEPIS/PUB, CD-ROM. 2002.
Endereço para correspondência:

Jeruza Feitosa de Matos Núcleo de Tecnologia Industrial (Nutec)

Rua Bento Albuquerque, $n^{\circ} 768$

Fortaleza - Ceará - Brasil 60190-080 - Tel.: (85) 3262-7765 E-mail: jfmatos@secrel.com.br

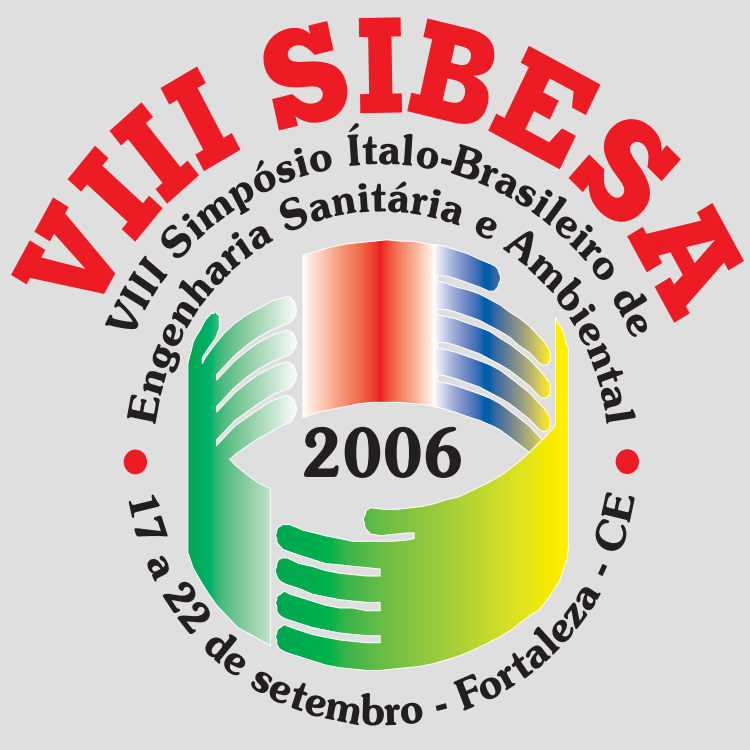

Promoção

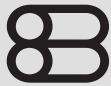

ABES ASSOCIACÃO BRASILEIRA DE ENGENHARIA SANITÁRIA E AMBIENTAL Capítulo Nacional da AIDIS

Realização

ABES - Seção Ceará 